\title{
Papillary Thyroid Carcinoma Developments After Radioactive lodine Treatment for Toxic Adenoma: A Case Report
}

\author{
Cevdet Duran ${ }^{\mathrm{a}, \mathrm{f}}$, Mustafa Cayci ${ }^{\mathrm{b}}$, Orkide Kutluc ${ }^{\mathrm{c}}$, Baris Sevinc ${ }^{\mathrm{d}}$, \\ Omer Karahan ${ }^{d}$, Samil Ecirlic ${ }^{c}$ Ceyhan Ugurluoglu ${ }^{\mathrm{e}}$
}

\begin{abstract}
Radioiodine is an important radiopharmaceutical agent in nuclear medicine practice for the treatment of hyperthyroidism and differenciated thyroid cancer. One of the long term side effects of ionising radiation is the possibility of radiation induced malignancy. There are limited reports about malignancy after ${ }^{131} \mathrm{I}$ therapy for thyrotoxicosis. In this report, a case with papillary thyroid cancer after radioactive iodine (RAI) therapy for toxic thyroid nodule is presented. In this case, fine needle aspiration biopsy(FNAB) had not been done before RAI therapy and papillary carcinoma was detected four years later than the $444 \mathrm{MBq}$ RAI therapy. The patient underwent bilateral total thyroidectomy and central neck dissection. After the surgery, the patient underwent $5550 \mathrm{MBq}$ RAI for ablation. Summary, differentiated thyroid cancer can be found incidentally in toxic nodule or can be developed as a consequence of radioiodine therapy. FNAB must be performed for all the patients with hot or cold thyroid nodules before RAI therapy and all the patients taking RAI theraphy should be closely followed in terms of nodule growing and cancer development.
\end{abstract}

Keywords: Thyroid cancer; ${ }^{131} \mathrm{I}$ therapy; Toxic adenoma

Manuscript accepted for publication August 12, 2013

\footnotetext{
${ }^{a}$ Division of Endocrinology, Department of Internal Medicine, Konya Training and Research Hospital, Meram Yeniyol, Konya, Turkey

${ }^{\mathrm{b}}$ Department of Nuclear Medicine, Konya Training and Research Hospital, Meram Yeniyol, Konya, Turkey

${ }^{\mathrm{c}}$ Department of Internal Medicine, Konya Training and Research

Hospital, Meram Yeniyol, Konya, Turkey

${ }^{\mathrm{d}}$ Department of General Surgery, Konya Training and Research

Hospital, Meram Yeniyol, Konya, Turkey

${ }^{\mathrm{e}}$ Department of Pathology, Konya Training and Research Hospital,

Meram Yeniyol, Konya, Turkey

${ }^{\mathrm{f}}$ Corresponding author: Cevdet Duran, Division of Endocrinology,

Department Internal Medicine, Konya Training and Research

Hospital, Meram Yeniyol, Meram, 42100, Konya, Turkey.

Email: drcduran@gmail.com
}

doi: http://dx.doi.org/10.4021/jmc1459w

\section{Introduction}

The usage of radioactive iodine (RAI) therapy for toxic goitre is increasing worldwide, so this issue is a public health problem [1]. RAI is an important radiopharmaceutical agent in nuclear medicine practice for the treatment of hyperthyroidism and differentiated thyroid cancer [2]. One of the longterm side effects of ionising radiation is the possibility of radiation induced malignancy. In the literature, many reports have been published in terms of radiation induced thyroid malignancy after Chernobyl accident [3, 4]. Likewise, it is reported that thyroid cancer can be developed after ${ }^{131}$ I therapy for thyrotoxicos [5-9]. It is also reported that ${ }^{131} \mathrm{I}$ therapy for diagnostic purpose does not increase the risk of thyroid malignacy although it is commonly used [10]. Besides, radiation exposure can cause thyroid malignancy, RAI therapy is recommended as the first choice for toxic adenoma by American Thyroid Association (ATA) without performing fine needle aspiration biopsy (FNAB). As there is no reported cancer case that developed from hot nodule, routine FNAB is not recommended by ATA $[11,12]$. In this report, a case with papillary thyroid cancer after RAI therapy for toxic thyroid nodule is presented.

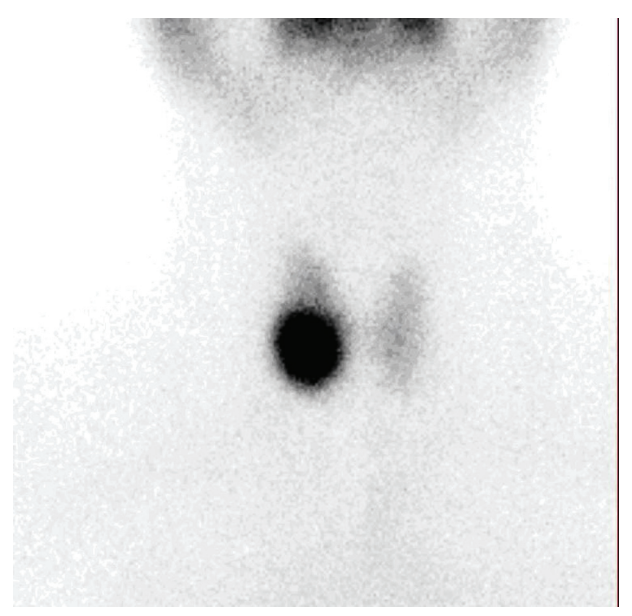

Figure 1. ${ }^{99 m}$ Tc scintigraphy showing a hot nodule at the right thyroid region. 


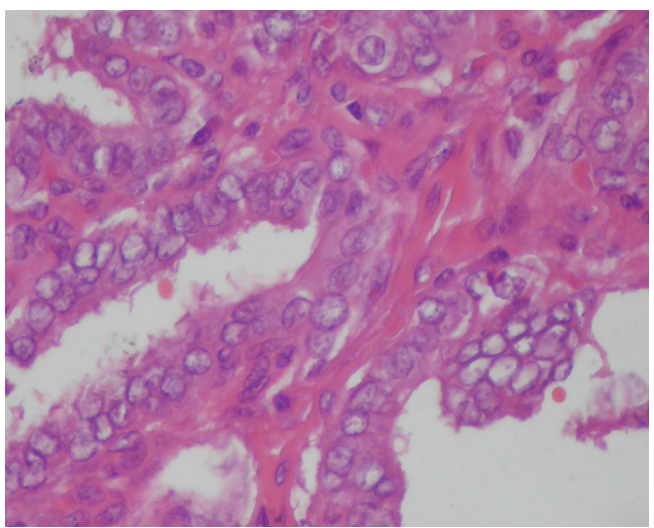

Figure 2. Thyroid histopathology showing tumor tissue composed of fibrovasculary core surrounded by papillary formations, partially enclosed by a thick fibrous capsule (Hematoxyline \& Eosine, $\times 80 \mathrm{HP}$ ).

\section{Case Report}

A thirty-four year old female patient was admitted to hospital for toxic adenoma in 2007. At the initial investigation, TSH, $\mathrm{FT}_{4}, \mathrm{FT}_{3}$, anti-thyroid peroxidase autoantibody and antithyroglobulin autoantibody (Anti Tg) levels were $0.189 \mu \mathrm{IU} /$ $\mathrm{mL}(\mathrm{N}: 0.35-5.5 \mu \mathrm{IU} / \mathrm{mL}), 1.48 \mathrm{ng} / \mathrm{dL}(\mathrm{N}: 0.85-1.78 \mathrm{ng} / \mathrm{dL})$, $3.26 \mathrm{pg} / \mathrm{mL}(\mathrm{N}: 157$ - $4.71 \mathrm{pg} / \mathrm{mL}), 133 \mathrm{IU} / \mathrm{mL}$ (N: 0 - $35 \mathrm{IU} /$ $\mathrm{mL})$ and $337 \mathrm{IU} / \mathrm{mL}(\mathrm{N}: 0-40 \mathrm{IU} / \mathrm{mL})$, respectively. Thyroid ultrasonography (USG) showed a calcified solid nodule with cystic degenarations, in a size of $2 \mathrm{~cm} \times 2.5 \mathrm{~cm} \times 2$ $\mathrm{cm}$, at right thyroid lobe and the ${ }^{99 \mathrm{~m}} \mathrm{Tc}$ thyroid scintigraphy showed a hyperactive/hot nodule at right thyroid lobe (Fig. 1). After the diagnosis, $444 \mathrm{MBq}(12 \mathrm{mci}){ }^{131} \mathrm{I}$ treatment was administered orally in June, 2007. After RAI therapy, patient remained in euthyroid status.

On January 2010, she was admitted at the hospital with

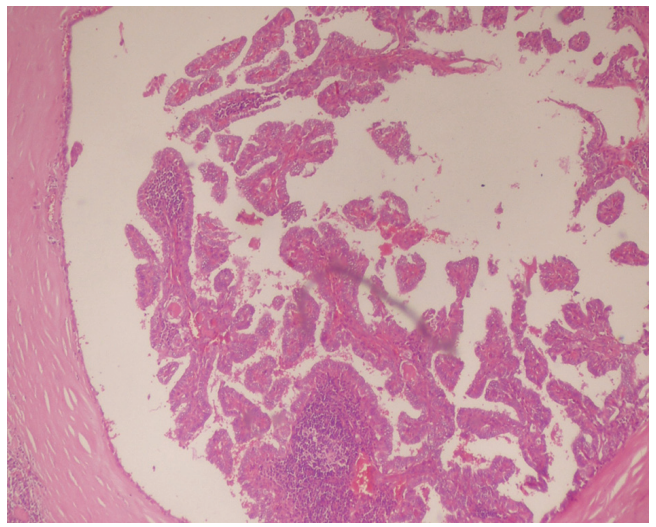

Figure 3. Thyroid histopathology showing atypical thyrocytes with pale and large nuclei containing glassy intranuclear inclusion bodies, lining the papillary projections. (Hematoxyline \& Eosine, × $200 \mathrm{HP}$ ).

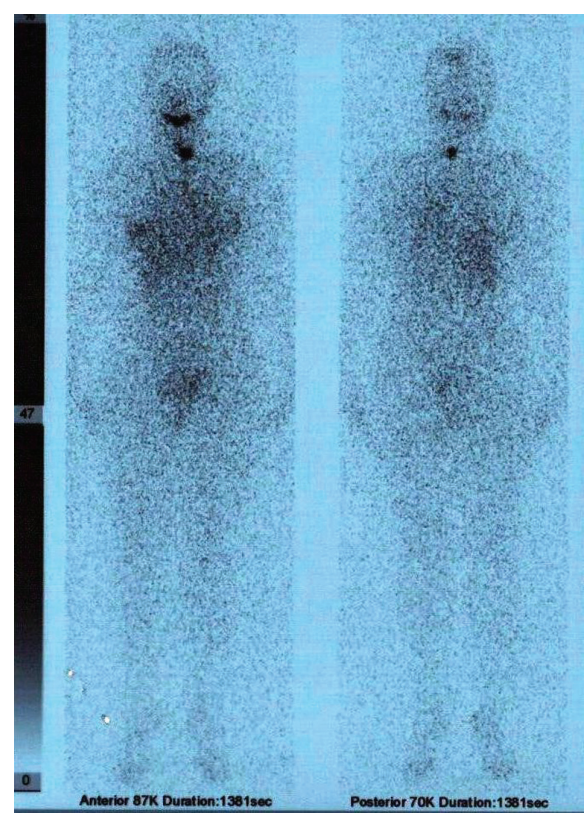

Figure 4. Post ablative $9^{\text {th }}$ day whole body ${ }^{131} \mid$ scan showing a remnant at the left thyroid bed.

a mass at the left side of her neck. After a physical examination, there was a palpable mobile mass at the left side of thyroid lobe. Thyroid USG showed two classified nodules at right thyroid lobe (9.5 and $10 \mathrm{~mm}$ in diameter), a heterogeneous mass with cystic areas and lobulated contours $(30 \mathrm{~mm}$ $\times 17 \mathrm{~mm} \times 44 \mathrm{~mm}$ ) at the left side of the cervical region and lymph node with narrow hilus at bilateral cervical regions, larger one measuring $11 \mathrm{~mm} \times 5.5 \mathrm{~mm}$. FNAB was performed and it revealed "papillary thyroid carcinoma" in the thyroid nodule at right lobe and "suspected for malignancy" in the mass at the left side.

On April 2011, the patient underwent bilateral total thyroidectomy with central lymph node dissection. The histopathological examination showed papillary carcinoma in size $1 \mathrm{~cm} \times 1 \mathrm{~cm} \times 1 \mathrm{~cm}$ at right thyroid lobe, $0.4 \mathrm{~cm}$ in left thyroid lobe and five metastatic lymph nodes at the left central neck (Fig. 2, 3). On L-thyroxine replacement therapy, post-operative serum TSH, thyroglobulin and anti Tg levels were $0.01 \mu \mathrm{IU} / \mathrm{mL},<0.2 \mathrm{ng} / \mathrm{mL}(1.6-59.9 \mathrm{ng} / \mathrm{mL})$ and 63.2 $\mathrm{IU} / \mathrm{mL}$, respectively.

On September 2011, the patient underwent $5550 \mathrm{MBq}$ $(150 \mathrm{mCi})$ radioiodine ablation therapy and post therapy, on the 9th day,the whole body scan revealed a remnant at the left thyroid region (Fig. 4).

\section{Discussion}

To the best of our knowledge, this is the first case reporting papillary thyroid cancer arising from toxic adenoma following RAI therapy. The prevalence of thyroid nodule increases 
with age and it is more common in women. Nearly less than $10 \%$ of all thyroid nodules are toxic [13]. Initial evaluation of all thyroid nodules require FNAB, however, as the rate of malignancy in toxic nodule is low and benign hyperfunctioning nodules may be cytologically indistinguishable from non functioning benign follicular neoplasms and follicular cancer, ATA doesn't recommend it for toxic ones [11]. It is reported that toxic nodules are almost never malignant and cold nodules are 5 - 8\% malignant [12].

The usage of RAI therapy for toxic goitre is increasing worldwide and the disadvantage of radioactive iodine therapy is the possibility of radiation induced malignancy. ${ }^{131} \mathrm{I}$ has relatively high photon energy $(364 \mathrm{keV})$, long half life (nearly 8 day) and the presence of beta particle emissions [2]. Latency period between radiation exposure and development of thyroid cancer ranges between a minimum of $3-7$ years and a maximum of $40-50$ years [3]. The risk of the development of thyroid malignancy decreases with age and after the age of 20 years the risk is less [3, 4]. In our patient, if we accept that the thyroid cancer developed as a consequence of first RAI therapy, there had been nearly 4 years between first RAI therapy and the diagnosis of cancer. This was consistent with the literature for the development of the thyroid cancer after radioiodine.

In the literature, there are few reports about thyroid cancer after RAI therapy for toxic nodulary or diffused goiter. Staffurth et al. reported a folliculary thyroid cancer following RAI therapy for Graves' disease [5]. In their case, FTC derived 17 years after the RAI therapy. Similarly, there are some reports of anaplastic thyroid cancer after RAI therapy for toxic goiter [6-9].

In the case, FNAB was not performed before the first RAI therapy. It is not known whether the cancer had been there before the therapy or it was developed after the therapy. Therefore, FNAB must be performed for all nodules before RAI therapy.

In conclusion, differentiated thyroid cancer can be found incidentally in toxic nodule or can be developed as a consequence of RAI therapy for toxic nodule. FNAB must be performed for all the patients with hot or cold thyroid nodules before RAI therapy and all the patients taking RAI theraphy should be closely followed in terms of nodule growth and cancer development.

\section{Acknowledgement}

Authors have no relevant conflict of to declare.

\section{References}

1. United Nations Scientific Commitee on the effects of
Atomic Radiation (UN-SCEAR). Exposure to the public from man-made sources of radiation radiation. (UNSCEAR) 2000 report to the general assembly, with scientific annexes. http://www.unscear.org/docs/reports/ annexc.pdf

2. Basic Principles, Radiopharmaceuticals. Ziessman HA, O'malley JP, Thrall JH (Eds). In: Nuclear Medicine. Elsevier Mosby Philadelphia, PA, 2006, Chapter 1, pp. 3-19.

3. Papadopoulou F, Efthimiou E. Thyroid cancer after external or internal ionizing irradiation. Hell J Nucl Med. 2009;12(3):266-270.

4. Cardis E, Howe G, Ron E, Bebeshko V, Bogdanova T, Bouville A, Carr Z, et al. Cancer consequences of the Chernobyl accident: 20 years on. J Radiol Prot. 2006;26(2):127-140.

5. Staffurth JS, Holl-Allen RT. Follicular carcinoma of the thyroid following radioactive iodine treatment for Graves' disease. Postgrad Med J. 1988;64(757):878880.

6. Maatouk J, Barklow TA, Zakaria W, Al-Abbadi MA. Anaplastic thyroid carcinoma arising in long-standing multinodular goiter following radioactive iodine therapy: report of a case diagnosed by fine needle aspiration. Acta Cytol. 2009;53(5):581-583.

7. Cannizzaro MA, De Maria A, Fazzi C, Mazzone G, Terminella A, Fiorenza G, Veroux PF. Anaplastic carcinoma of the thyroid: long-term survival. Minerva Chir. 1993;48(21-22):1293-1299.

8. Hayes FJ, Sheahan K, Heffernan A, McKenna TJ. Aggressive thyroid cancer associated with toxic nodular goitre. Eur J Endocrinol. 1996;134(3):366-370.

9. Vescini F, Di Gaetano P, Vigna E, Pascoli A, Cacciari M. Anaplastic thyroid carcinoma in a 49 year-old woman with a long-standing goiter. A case report. Minerva Endocrinol. 2000;25(3-4):81-83.

10. Dickman PW, Holm LE, Lundell G, Boice JD, Jr., Hall P. Thyroid cancer risk after thyroid examination with 131I: a population-based cohort study in Sweden. Int J Cancer. 2003;106(4):580-587.

11. Mazzaferri EL. Management of a solitary thyroid nodule. N Engl J Med. 1993;328(8):553-559.

12. Gharib H, Papini E, Valcavi R, Baskin HJ, Crescenzi A, Dottorini ME, Duick DS, et al. American Association of Clinical Endocrinologists and Associazione Medici Endocrinologi medical guidelines for clinical practice for the diagnosis and management of thyroid nodules. Endocr Pract. 2006;12(1):63-102.

13. Singer PA, Cooper DS, Daniels GH, Ladenson PW, Greenspan FS, Levy EG, Braverman LE, et al. Treatment guidelines for patients with thyroid nodules and welldifferentiated thyroid cancer. American Thyroid Association. Arch Intern Med. 1996;156(19):2165-2172. 